[Dixon, H., \& Williams, R. (2003). Teachers' Understanding and Use of Formative Assessment in Literacy Learning. New Zealand Annual Review of Education, 12, 95-110]

\section{Teachers' Understanding and Use of Formative Assessment in Literacy Learning}

\author{
HELEN DIXON AND RUTH WILLIAMS
}

\section{Abstract:}

Since 1999, successful literacy learning for all children has been a focal point of government policy as outlined in the Report of the Literacy Taskforce. Specified in the report is the need to raise standards of achievement for all students and to close the gap between high and low achievers. To achieve these goals, teachers must be able to understand the nature and function of formative assessment in the teaching/learning process, and also to utilise information formatively. Recent research shows that while teachers accept the basic premise that assessment has a positive role to play in the promotion of student learning, they are not able to articulate clearly how they utilise assessment information to enhance learning (Dixon, 1999; Hill, 2000).

This article reports on teachers' understandings about, and use of, formative assessment with years one to eight children in the areas of reading, written language and oral language. It concludes that while teachers appear to have increased their theoretical understanding of formative assessment, their descriptions of practice omit a number of critical components which are essential to successful learning for children.

L

iteracy learning (and teaching) has been the focus of significant attention in recent years, with the aim of ensuring that by 2005 "every child turning nine will be able to read, write, and do maths for success" (Ministry of Education, 1999, p. 4). In outlining the national literacy strategy, the Literacy Taskforce has emphasised the need for high quality teaching that builds on a "child's existing skills, knowledge, interests and individual needs and that will acknowledge the role of the learner as an active participant" (p. 12). The critical role that assessment plays in the promotion of learning is discussed in latter sections of the

\section{Helen Dixon and Ruth Williams}

report, where it is emphasised that the data collected must be utilised in an ongoing manner. Implicit throughout much of the document is the need for teachers and learners to engage in formative assessment.

Much has been written in recent times about formative assessment, with considerable debate occurring about its role in the raising of levels of achievement (Black \& Wiliam, 1998, p. 7). As it is now conceptualised, formative assessment has come to incorporate notions of identifying progress and providing feedback to students through the use of strategies that will support and promote deep rather than surface learning (Pryor \& Torrance, 1997). This implies a more dynamic, interactive and challenging role for teachers as they are charged with the responsibility of being responsive to student need, intervening where necessary as teaching and learning are occurring. However this conception of formative assessment is both ambitious and complex, in that it requires teachers to have an understanding of constructivist theories of learning (Black, 2000; Shepard, 2000). It also necessitates a significant shift in teachers' thinking about assessment that requires them to relinquish previously held conceptions about the place and role of assessment in learning.

A number of New Zealand studies have investigated teachers' understandings of formative assessment and have provided descriptions of what formative assessment might look like in practice (Bell \& Cowie, 2001; Dixon, 1999; Hill, 2000). Research investigating teachers' formative assessment practice has led to the identification of two types of formative activity. Planned or formal formative assessment is teacher-focussed and relates to the planning and assessment that teachers develop prior to or during the course of a lesson (Bell \& Cowie, 1997; Harlen, 1998). Brainstorming to find out children's prior knowledge before commencing a unit study, or questioning at the beginning of a lesson to check on children's understandings, typify the activities associated with planned formative assessment. In comparison, interactive or informal formative assessment is embedded in the teaching and learning process, as teachers work with small groups or individuals. Although teaching is planned for, teachers realise that learning is unpredictable and idiosyncratic. Interactive formative assessment can best be described as teacher- and child-driven rather than curriculumdriven. It relates to individual children's needs at the time, rather than achievement in relation to pre-specified learning outcomes. In noticing, recognising and responding to student thinking, teachers become mediators in the learning process. 
Feedback is an essential component of formative assessment (Sadler, 1998, p. 84), and is one of a number of inter-connected learning and teaching strategies, such as goal-setting, self assessment, questioning and dialogue, which, if used appropriately, will lead to the active involvement of learners in a culture of learning (Assessment Reform Group, 1999; Hargreaves, McCallum \& Gipps, 2000). The feedback process must allow for opportunities to communicate with and to learners (Hattie \& Jaeger, 1998). Therefore observing, talking with, and listening to children as they are engaging in the learning task, as well as providing a forum whereby children can receive feedback and review their own work in light of this, are necessary features of formative practice. Recent studies, however, have shown that feedback to the learner is either typically low (Black \& Wiliam, 1998) or has little or no relationship to the learning taking place (Pryor \& Torrance, 1997). To construct a way forward for the learner, feedback must:

- be accessible to and understood by the learner;

- have a catalytic and coaching value which will inspire confidence and hope in the learner;

- enable the learner to identify gaps between current and desired performance, and to take some action which will close that gap (Sadler, 1998, p. 84).

The expectation that learners will identify gaps in their knowledge and performance, and will take effective action to close the gap, places them in a pivotal role within the learning process, one that requires sophisticated metacognitive skills. To improve and enhance performance, learners must be able both to evaluate their levels of achievement (including strengths and weaknesses) and to regulate their subsequent actions in the application of that knowledge (Flavell, 1987). Fundamental to this process is the need for the learner to have a clear idea of the learning goals of the task, and what is required for successful completion. Research findings are a cause for concern when it is revealed that teachers often closed down opportunities for exploring student understanding, placed little emphasis on sharing learning goals with students and rarely clarified the purpose of classroom activities to their students (Torrance \& Pryor, 2001). Recent research would suggest that learners must be involved in self-regulatory mechanisms such as checking, monitoring, revising and evaluating, as these are essential aids to scaffold the metacognitive process. (Hine, 2000).
Teachers also need to have what Shulman (1987) has termed the knowledge bases of teaching. They need a thorough and deep understanding of the subject matter (and content to be taught), for without this knowledge, teachers are not able to ask the right questions, anticipate conceptual pitfalls or develop a repertoire of tasks that will assist students to take the next learning steps (Shepard, 2000). This requirement is especially difficult for primary school teachers, who are required to teach many subjects across seven essential learning areas. Furthermore, teachers require knowledge of:

- how children learn, both individually and developmentally;

- children's entry levels and the specific nature of their problems;

- the progression of ideas within a given topic; and

- general and specific pedagogical content knowledge so that they can utilise a range of strategies to elicit and act on students' ideas.

Harlen and James (1997) found that the lack of distinction between formative and summative assessment evident in policy documents had a significant effect on teachers' practice. As teachers struggled to complete assessments for two distinct purposes, these became confused. Consequently, little genuine formative assessment was evident. Significantly, if formative assessment was occurring, teachers were unaware of it. Often teachers believed they were assessing formatively, but were in reality completing on-going summative assessments that they then used primarily for reporting purposes. Studies by Bell and Cowie (1997), Dixon (1999), and Hill (2000) have reported very similar findings.

Longitudinal research projects undertaken by Hargreaves, McCallum and Gipps (2000), and Torrance and Pryor (1998, 2001) indicated that while teachers have accepted the basic argument that assessment has a positive role to play in the promotion of student learning, the teacher's role and that of the learner in formative assessment was inadequately understood and explicated. Furthermore, they found that teachers generally had a limited theoretical understanding of how assessment could and should be integrated into the learning/teaching process. Additionally, the research undertaken by Torrance and Pryor revealed that teachers had limited knowledge of theories of learning and their relationship to theories and methods of assessment (1997, pp. 119-120). As Sadler (1998) noted, even after several decades of research into formative assessment, there still 
remains much that is unresolved and problematic and much that warrants further investigation.

This article will make use of a recent research project to shed light on some of these issues.

\section{Methodology}

Aims

The intent of the research was to investigate teachers' understandings of formative assessment. Specifically, the study aimed to:

1. Identify teachers' perceptions of the key differences between formative and summative assessment;

2. Ascertain how teachers utilised assessment information, particularly in the areas of reading, written and oral language;

3. Identify factors that have shaped and influenced teachers' understandings and use of formative assessment.

Findings in regard to the first two aims of the project will be discussed here.

\section{Sample}

The research was undertaken with 40 primary school teachers: 10 teaching at each of the following class levels: years one and two; years three and four; years five and six; and years seven and eight. Teachers within each of the year groupings were selected randomly from the Auckland College of Education's directory of associate teachers.

\section{Procedure}

Data were gathered by semi-structured audio-taped interviews that were analysed qualitatively and quantitatively. Data gathered were collated under each of the interview questions. This was followed by a quantitative analysis to determine frequency of responses. Broad categories and emerging themes related to the three major aims of the project were then identified. Establishing such categories and themes is a central element of the analysis process (Hammersley \& Atkinson, 1983) and in this study descriptive and conceptual categories were created to make sense of the data. Mason (1994) has defined descriptive categories as lists of substantive topics which can be used to index transcripts, whereas conceptual categories are those grounded in theoretical perspectives which aim to tease out aspects of the data relevant to the research questions.

\section{Findings}

Teachers' understandings of formative assessment

Past research hasidentified a fundamental confusion in teachers' minds related to the nature and purpose of formative assessment. It is encouraging to note that teachers in the present study had a much clearer understanding of formative assessment than previous research would indicate (Hill, 2000; Torrance \& Pryor, 1998). At a theoretical level, teachers were able to explain the main distinction between formative and summative assessment and identify some of the key characteristics of formative assessment. Significantly, when asked to describe their formative assessment practice, there were noticeable gaps and confusions in their articulated understanding of formative assessment. For example, the use of feedback to promote and enhance learning was rarely mentioned by teachers. Furthermore, only a few teachers talked of the importance of setting and sharing goals with learners, something which is now considered to be an integral part of formative assessment (Assessment Reform Group, 1999). This is not surprising, in view of current theories of formative assessment that require teachers to reconceptualise their concepts of learning and teaching. Indeed, researchers such as Hargreaves (1998) argue that teachers need time to translate theory into practice, and this will only occur through programmes of "development and dissemination which are matched to the capacity of teachers to take ownership of change, and the same time to rebuild their theories in a form that supports and gives coherence to practice" (cited in Black, 2000, p. 410).

\section{Teachers' use of formative assessment}

A key intention of this study was to ascertain how teachers used assessment formatively in the areas of reading and written and oral language. The selection of these specific curriculum areas was based on the belief that traditionally New Zealand teachers have felt confident and competent in the teaching of literacy, and therefore it could be assumed that they would be reasonably confident in the assessment of such areas. Several studies (Dixon, 1999; McCallum et al., 1995) have shown that both teacher confidence and content knowledge in a particular curriculum area are linked to an ability to assess children's learning. Ball and Bass (2000) have argued that unless teachers have sufficient content knowledge they will have difficulty noticing gaps and contradictions in children's learning, and will be unable to utilise children's existing knowledge to promote new learning. 


\section{Written language}

The teaching and assessment of written language provided the most specific examples of the ways in which teachers were able to use assessment information formatively. In this area teachers were most able to respond to the assessment information they gained as children were engaged in a variety of activities:

Some of my kids they just write a whole list of letters and they don't actually separate the letters ... they don't see chunks of letters as words .... Just by looking at their writing that's something I need to address ... so that would be my teaching point." (Teacher \#1)

All of the teachers expected to work and respond to children in an individualised manner:

I use daily monitoring [with 26 children] ... I can see there is a need and it's really done on an individual conferencing basis ... I would say that almost every child I have here I could tell you exactly where they are at with written language and I would [know] exactly in my head where I am going to the next stage with them. (Teacher \#4)

Teachers used conferencing frequently and found it a useful way of collecting and utilising assessment information. They were able to provide a number of illustrative examples of the ways in which learning could be supported as children were set relevant activities and given appropriate help as the teacher worked alongside them, challenging their previously held conceptions and practices:

In the conference situation I get them to read through their work and

I'll ask them to think about what they are writing by asking questions

... the who, what, why, when questions to make them think more about their story and the message ... then sometimes I'll write down a question [in the book] and direct them to that, they'll go off and have to think of another bit to add so it's like getting their story a bit more beyond where they were." (Teacher \#1)

Sadler $(1989,1998)$ has argued that it is the nature and quality of the interaction between teacher and pupil that determines whether or not learning will be enhanced. Teachers, when discussing the type of interactions they had with children during this conferencing activity, stressed the importance of identifying areas that children needed to practice or work on if they were to move forward in their development of understandings and skills. Providing opportunities which enabled teachers to observe and work alongside children, listening to them talking out loud and investigating their own errors, were seen as critical strategies to enhancing learning. As one teacher noted when working with emergent writers:

[At the conference] I would give him confidence by acknowledging the story and how good it is or whatever but then I'd pick up on one thing they may need to work on, whether it be finger spacing, or capital letters or can you hear the sound in this word? (Teacher \#8)

In the majority of instances, teachers used assessment information intuitively, storing it in their head for future use, rather than recording it in any formal way. Any recorded information was used in a planned formative way in that it served as a reminder for future teaching (Bell \& Cowie, 1997). Teachers reported that they did not document this information for summative purposes.

The teachers did not group children for written language. Whole class teaching was common practice. This a pplied across all year groups. The planned use of formative assessment was evident when teachers talked of constructing a group for specific instructional purposes. In this way a teaching episode arose out of the teacher's identification of children's needs. Teachers working in the middle and senior levels of the primary system reported that children's draft writing books provided them with insights into children's writing. Subsequently, these insights were used for planning and teaching purposes:

I tend not to use set groups.... I prefer to bring out groups if there is a common need ... we've all got this problem ... [Looking through children's writing books] I find that even though the kids are really capable readers they are not necessarily transferring what they see in a book ... paragraphing is a big issue so I'll go back and say look at your paragraphing, circle the beginning of the paragraph and they'll come back to me and we'll have a look at we'll talk about what needs to happen and how big the paragraph will be and where to insert it. (Teacher \#25)

Many writers emphasise the importance of involving children in the assessment process, believing that this will help them understand more about the learning that is occurring, and assist them to promote and enhance that learning (Sadler, 1989). In this way decisions can be made not only by the teacher but by the children themselves, thus encouraging and empowering children to take responsibility for their own learning. Some teachers noted that key information gathered during conferencing was written down in the children's books. Thus 
children themselves could be cognisant of what they needed to practice to reach the next learning step:

[Children's writing goals] gets put in the back of the children's books because that's the individual thing ... I make the children aware of when I've written it in and I'll say this is what you need to concentrate on so hopefully it reminds them of what it is. (Teacher \#6)

I think its really important that children know what they are trying to learn ... part of it is to let them know what they need to be learning and you can write it down. I've tried a lot of different ways of goal setting so they are aware of it so that you are looking for it so they notice it from the start. (Teacher \#12)

This however was not common practice. When asked, the majority of teachers in the study reported that they did not share learning goals with children.

\section{Reading}

While the teachers provided examples in written language that were more consistent with what Bell and Cowie (1997) have described as the interactive use of formative assessment, the same could not, in general terms, be said for reading. With regard to reading, the planned use of formative assessment was far more evident. Running records were considered by all teachers to be a valuable source of information to: identify a child's current level of instruction; confirm the teacher's judgement that the child should be moved up a level or to group children for further instruction. Interestingly, as opposed to the situation in written language, teachers tended to talk about group rather than individual needs when talking of specific teaching episodes:

... whether they [the children] are using strategies ... so that you can use that as a focus for the group and your work and if the children in that group aren't self correcting ... and I'll use that for teaching points through the books [instructional readers]. (Teacher \#2)

I sit down with my red folder [a tracking book] and look into a group and think about who summarises well, who's doing the predicting and then try to focus on those things with the group ... and then maybe just help them through to do an article. (Teacher \#11)

Only a few teachers discussed the importance of analysing running records for specific cues related to an individual's reading behaviour.
These teachers emphasised the importance of being able to identify children's actual reading behaviours so that they could teach to their specific needs. They also explained that information gained from the running record must be shared with the children so they are aware of the strengths and weaknesses of their reading behaviours and strategies. They felt this was especially important for those children who had experienced difficulties in reading. However, as the literature would suggest, this knowledge is critical for all children if changes in performance are to occur.

To a lesser extent, teachers - generally those who had been trained in reading recovery techniques - talked of how they were able to elicit, interpret and utilise assessment information as they were working with children:

... perhaps in reading when you notice something when you are reading with a child or talking with them ... and they might tell you oh I can do that now... they might say it to you or you might say it to them. Oh I've noticed something you have been having difficulty working out, you can do this, excellent. And often children come and tell me oh I can do this now, or I know what these [contractions] are now. (Teacher \#12)

\section{Oral language}

The oral, written and visual components of language are considered to be both extremely complex and highly interrelated (Clay, 1991, p. 27). Indeed the report from the Literacy Task force to the Ministry of Education (Ministry of Education, 1999) posited that children's success in reading and writing is dependent upon the knowledge and skills they have acquired in the listening and speaking domains. These are important dimensions of learning, and teachers need to be able to focus on them, in order to make valid analyses of students' skills, knowledge and understandings which will form the basis of what children know and can do (Crooks \& Flockton, 1998). However, a previous study (Williams \& Dixon, 1998) found that teachers had difficulty in interpreting and utilising the assessment information gained in oral language situations. Within the context of the present study, while teachers were able to focus on a number of important learning dimensions in written language and reading, in varying degrees, they were less able to do this in the area of oral language.

In general, teachers were unable to explain clearly how they assisted children's learning in the area of oral language. Mainly, they talked 
about focussing on general aspects of oral language, emphasising the development of children's speaking and listening skills and the ways in which they attempted to increase children's participation in speaking and listening activities.

Teachers attempted to meet children's oral language needs through the provision of whole class activities rather than through individualised or group instruction. However, individual children who were perceived to have more severe or extreme needs were referred on to more expert "others" such as speech language therapists.

In a few instances, teachers talked specifically of catering to individual or group needs in the area of oral language. One junior school teacher provided a number of illustrative examples of the way in which group needs were catered for in a planned formative way. Using children's individual writing responses and their four week oral language sample as a basis for action, she planned specific activities which aimed to increase children's vocabulary or address specific grammatical needs:

We go through as a team [syndicate] and check and see which children have got good vocabulary and then the ones that have poor grammar ... we focus on those things in our planning ... we think we must do more vocabulary building with them [ a group] ... we do it as groups and we split the children up ... and then we can retest, children change and shift around [groups]. (Teacher \#8)

Several other teachers, from a range of class levels, talked about the importance of increasing children's awareness and use of vocabulary and grammar as vehicles to both express and extend children's thinking:

Before we do any writing I spend a lot of time getting children to express their ideas orally, to me and to each other. If they can not express their ideas orally then it is very difficult for them to write them down. I try to help the children understand the connection between writing and speaking. (Teacher \# 18)

Significantly these teachers understood the relationship between oral language, reading and writing. They were clear about the specific content they wanted to teach.

Of concern however, was the number of teachers who neither collected, analysed nor utilised assessment information related to children's oral language. While the teachers in this study were confident in their ability to assess children's learning in reading and writing, this did not necessarily transfer over into the oral language area. In part, this was explained by the teachers themselves as a perceived lack of a number of critical knowledge bases. Specifically, these teachers felt that they lacked both content knowledge and knowledge of the developmental stages children go through in the acquisition of oral language. These in turn inhibited their ability, both to assess where children were at, and to move them forward to the next learning step.

\section{Implications}

While teachers were able to describe their use of assessment information formatively in the areas of reading and writing, written language was the one area where they could provide examples of the interactive use of formative assessment. However these examples themselves were limited. In attempting to clarify the links between formative assessment and constructivist theories of learning, recent literature has emphasised the need to share learning goals with children (Black, 2000a) and to incorporate feedback into the scaffolding process (Shepard, 2000). While most teachers discussed the importance of working with and alongside children, in the majority of cases their discussion did not include reference to sharing learning goals with children, or the importance of providing them with feedback. We (as the researchers) are not yet clear why these important facets of formative assessment a ppear to be absent from teachers' descriptions of their own practice. However if we are serious about encouraging children to become active participants, and truly believe that active involvement will lead to successful outcomes for learners, as is stated in the Literacy Taskforce recommendations, then this aspect of teachers' practice warrants further investigation.

It was noticeable that when teachers articulated their assessment practice in reading, the planned use of formative assessment dominated. Consistent with the findings of Harlen and James (1997), it appeared that if teachers were using interactive formative assessment, it was in an unconscious manner. It would appear that if monitoring, analysis and reflection are to be an integral part of teaching (Ministry of Education, 1999, p. 25) then teachers need more assistance in understanding and using interactive formative assessment (Hill, 2000). If we are to increase teachers' knowledge of formative assessment, then this needs to be the focus of professional development programmes and initiatives. In our opinion there needs to be a consistent approach 
nation-wide that focuses teachers' attention on both the theoretical and conceptual notions underpinning formative assessment and deconstructing their current pedagogical practices.

Although experts in the field of literacy have stressed the interrelationship between oral, visual and written language, this relationship was not so evident in teachers' talk in the present study. While language experts have argued that oral language provides the basis for future success in reading and writing (Ministry of Education, 1999 , p. 12), this was an area that teachers, generally, were not confident in. They displayed limited knowledge both of how to teach children and how to assess their learning in oral language. This is a major concern, when one of the principles of best practice outlined in the taskforce report is that good language programmes will "acknowledge the inter-relationship and reciprocity of oral, written and visual language" (p. 12).

Researchers such as Shulman (1987) contend that if teachers are to be effective in their practice, they need a number of knowledge bases: indepth knowledge of the subject they are teaching, an awareness of the progressions that children move through in learning, and knowledge of how to teach a subject effectively. The present study has highlighted what appears to be a gap in teachers' knowledge in all these areas in relation to oral language.

\section{Conclusion}

A final note: While this sample of 40 teachers displayed a theoretical understanding of the nature, place and purpose of formative assessment in the teaching learning process, this at times became confused when they were describing aspects of their practice. Although teachers were aware of the need to provide learning experiences that would promote interactions with learners, their narratives of significant incidents in the learning and teaching of reading, writing and oral language often failed to mention a number of the critical components of formative assessment such as feedback and goal setting. Furthermore the role of learner in the assessment process was under-rated. However, the accuracy of such findings, based on teachers' descriptions of their practice, needs to be validated through observation of classroom practice.

A first step to improving literacy outcomes for all children, and closing the gap between low and high achievers is to improve teachers' formative assessment practice. In professional development programmes supporting the national literacy strategy there needs to be a far greater emphasis on how children learn and how teachers can become mediators of learning. To achieve this end teachers must have

a better theoretical understanding of social constructivism and metacognition. Unless this occurs, assessment will always sit outside of learning, and teachers and learners will always play traditional rather than contemporary roles in the learning/teaching (and assessment) process.

In terms of children's learning, teachers need to know what they should be looking for. They need to have subject knowledge and knowledge of the sequential processes of children's learning (Shepard, 2000), a better knowledge of how to analyse assessment data, and a better knowledge of how to use data to enhance children's learning.

\section{References}

Assessment Reform Group. (1999). Assessment for learning: Beyond the blackbox. Cambridge: University of Cambridge, School of Education.

Ball, D., \& Bass, H. (2000). Interweaving content and pedagogy in teaching and learning to teach: Knowing and using mathematics. In J. Boaler (Ed.), Multiple perspectives on mathematics teaching and learning (pp. 83-104). London: Ablex Publishing.

Bell, B., \& Cowie, B. (1997). Formative assessment and science education. Report of the Learning in Science Project (Assessment). Hamilton: University of Waikato, Centre for Science, Mathematics, Technology Education Research.

Black, P. (2000). Research and the development of educational assessment. Oxford Review of Education, 26, 3\&4, 407-419.

Black, P., \& Wiliam, D. (1998). Assessment and classroom learning. Assessment in Education: Principles, Policy \& Practice, 5(1), 7-74.

Clay, M. (1991). Becoming literate: The construction of inner control. Auckland: Heinemann.

Crooks, T., \& Flockton, L. (1998). Listening and Viewing Assessment Results. National Education Monitoring Report 10. Dunedin: University of Otago, Educational Assessment Research Unit.

Dixon, H. (1999). The effects of policy on practice: An analysis of teachers' perceptions of school based assessment practice. Unpublished MEdAdmin thesis, Massey University, Palmerston North, New Zealand. 
Flavell, J. (1987). Speculations about the nature and development of metacognition. In F. Weinert \& R. Kluwe (Eds.), Metacognition, motivation and understanding (pp. 21-29). New Jersey: Lawrence Erlbaum Associates.

Hammersley, M., \& Atkinson, P. (1983). Ethnography: Principles in practice. London: Tavistock.

Harlen, W. (1998). Classroom assessment: A dimension of purposes and procedures. Paper presented at the Annual Conference of the New Zealand Association for Research in Education, University of Otago, Dunedin, December.

Harlen, W., \& James, M. (1997). Assessment and learning: Differences and relationships between formative and summative assessment. Assessment in Education: Principles, Policy \& Practice, 4(3), 365-379.

Hattie, J., \& Jaeger, R. (1998). Assessment and classroom learning: A response to Black and Wiliam. Assessment in Education: Principles, Policy \& Practice, 5(1), 111-122.

Hill, M. (2000). Dot, slash, cross: How assessment can drive teachers to ticking instead of teaching. set, 1, 21-25.

Hine, A. (2000). Mirroring effective education through mentoring and metacognition. <www.aare.edu.au/00pap/hin00017.htm>

Mason, J. (1994). Linking qualitative and quantitative data analysis. In A. Bryman \& R. Burgess (Eds.), Analysing qualitative data (pp. 89-110). London: Routledge.

McCallum, B., Hargreaves, E., \& Gipps, C. (2000). Learning: The pupil's voice. Cambridge Journal of Education, 30(2), 275-289.

Ministry of Education. (1999). Report of the Literacy Taskforce. Wellington: Ministry of Education.

Pryor, J., \& Torrance, H. (1997). Making sense of formative assessment. International Studies in Educational Administration, 25(2), 115-125.

Sadler, R. (1989). Formative assessment and the design of instructional systems. Instructional Science, 18, 119-144.

Sadler, R. (1998). Formative assessment: Revisiting the territory. Assessment in Education: Principles, Policy \& Practice, 5(1), 77-84.

Shepard, L. (2000). The role of assessment in a learning culture. Educational Researcher, 29(7), 4-14.

Shulman, L. (1987). Knowledge and teaching: Foundations of the new reform. Harvard Educational Review, 57, 1-22.
Torrance, H., \& Pryor, J. (2001). Developing formative assessment: Using action research to explore and modify theory. British Educational Research Journal, 27(5), 615-631.

Tunstall, P., \& Gipps, C. (1995). Teacher feedback to young children in formative assessment: A typology. Paper presented at the IAEA Conference, Montreal, June.

Williams, R., \& Dixon, H. (1998). School Entry Assessment: Praiseworthy or perilous? SAMEpapers. Hamilton: University of Waikato, Centre for Science, Mathematics, Technology Education Research.

\section{The authors}

Helen Dixon is a Principal Lecturer at the Auckland College of Education, with teaching and research interests in formative assessment, learning and metacognition, developed from her teaching experience in the primary (including Special Education) and tertiary sectors. She is currently leading a collaborative research project with five Decile 1 schools, investigating the ways in which the decileweighted resource allocation is used within these schools.

Ruth Williams is currently the Acting Programme Leader for the Bachelor of Education (Teaching) Degree at the Auckland College of Education. Formerly assistant principal in a multicultural primary school and principal of a special school, her research interests are in assessment, the changing nature of teachers' work, and teacher professional development. 